\title{
Hepatoid adenocarcinoma of the lung
}

\author{
Lívia Barreira Cavalcante ${ }^{a}$ Aloísio Felipe-Silvab, \\ Fernando Peixoto Ferraz de Campos ${ }^{c}$, João Augusto dos Santos Martines ${ }^{d}$
}

Cavalcante LB, Felipe-Silva A, Campos FPF, Martines JAS. Hepatoid adenocarcinoma of the lung. Autopsy Case Rep [Internet]. 2013;3(1): 5-14. http://dx.doi.org/10.4322/acr.2013.002

\section{ABSTRACT}

Lung adenocarcinomas with a mixture of tubular or papillary pattern, sheet-like or trabecular architecture, eosinophilic cytoplasm with centrally located nuclei and alpha-fetoprotein-producing cells have been described as hepatoid adenocarcinomas. Hepatoid adenocarcinomas are mainly found in the stomach but rare cases in other organs have been described. Immunostaining for alpha-fetoprotein (AFP), hepatocyte paraffin 1 (HepPar-1) and thyroid transcription factor-1 (TTF-1) helps in the diagnostic workup. Tumor behavior is still not entirely known but it seems to be associated with early metastases. We report on a 66-year-old, heavy-smoker male patient who had a 10-month history of respiratory complaints and weight loss. At the time he was hospitalized, respiratory failure was already established. The computed tomography corresponded to a collapsed right lung due to a poorly defined expanding mass. The bronchoscopy revealed narrowing of the inferior and medium lobar bronchi. The patient developed irreversible shock and died. At the right lung inferior lobe was extensively replaced by a grayish diffuse neoplasia in a "pneumonia-like" gross pattern. Metastatic disease was found in the right adrenal gland and thoracic and abdominal lymph nodes. Microscopic dissemination through lymphatics, pleura, and airways was detected. Histological examination revealed a poorly differentiated adenocarcinoma with hepatoid features. Immunohistochemmistry stains were positive for keratin 7, polyclonal carcinoembryonic antigen (CEA) in a diffuse pattern, AFP and HepPar-1 antibody. TTF-1 showed a diffuse granular cytoplasmic staining of the neoplastic cells, and only focal nuclear positivity. Multiple bilateral emboli originated from deep venous thrombosis were present in large and medium branches of the pulmonary artery and contributed to the cause of death.

Keywords: Adenocarcinoma; Lung Neoplasms; Carcinoembryonic Antigen; Pulmonary Embolism; Autopsy.

\footnotetext{
a Department of Pathology - Hospital das Clínicas - Faculdade de Medicina - Universidade de São Paulo, São Paulo/SP - Brazil.

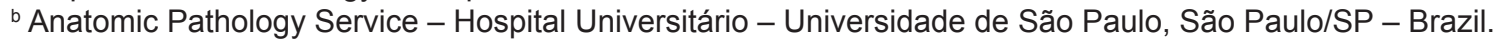

c Department of Internal Medicine - Hospital Universitário - Universidade de São Paulo, São Paulo/SP - Brazil.

d Diagnostic Imaging Service - Hospital Universitário - Universidade de São Paulo, São Paulo/SP - Brazil.
}

Copyright $\odot 2013$ Autopsy and Case Reports - This is an Open Access article distributed of terms of the Creative Commons Attribution NonCommercial License (http://creativecommons.org/licenses/by/3.0/) which permits unrestricted non-commercial use, distribution, and reproduction in any médium provided article is properly cited. 


\section{CASE REPORT}

A 66-year-old, black, male patient sought medical attention because of a 10-day history of productive cough and dyspnea. He referred respiratory complaints, recurrent pneumonia and weight loss during the last 10 months, raising the suspicion of lung cancer by the primary care physician. His past medical history was uneventful, but he had been a heavy smoker for 40 years.

Physical examination showed an ill-looking patient, emaciated, pale, showing mild respiratory distress. Blood pressure $=160 / 110 \mathrm{mmHg}$, pulse rate $=112$ beats per minute, respiratory rate $=32$ respiratory movements per minute, and room air pulse oximetry $=83 \%$. Edema was present in lower limbs. Lung examination revealed decreased bronchial breath sounds in the right hemithorax and scattered crackles. Cardiac and abdominal examinations were normal. Initial treatment comprised supplementary $\mathrm{O} 2$ by nasal catheter and antibiotics. The patient was hospitalized for further investigation.

The initial laboratory tests are in Table 1.

Room air gasometry revealed: $\mathrm{pH}=7.44$; $\mathrm{pO}_{2}=52 \mathrm{mmHg} ; \mathrm{pCO}_{2}=44 \mathrm{mmHg} ; \mathrm{HCO}_{3}=28 \mathrm{mEq} / \mathrm{L}$; $\mathrm{BE}=3.7$, and oxygen saturation $=88 \%$. Chest radiography showed diffuse and homogeneous opacity of the right hemithorax and right bronchus

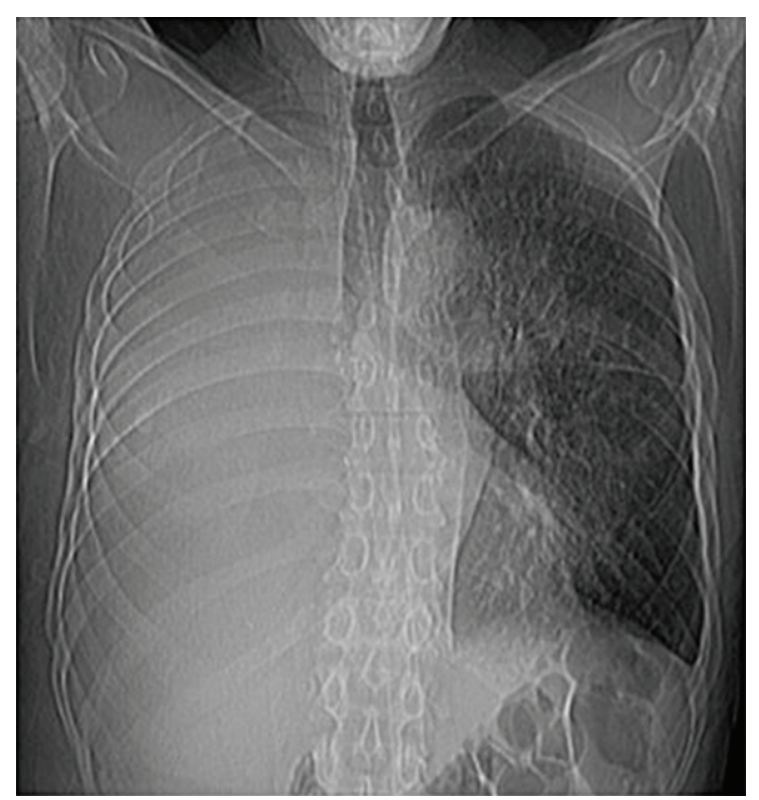

Figure 1 - Complete opacification of the right hemithorax. Note obliteration of ipsilateral main bronchus and foci of perihilar alveolar opacity on the left lung. obliteration without a significant deviation of the mediastinum, suggesting pulmonary atelectasis associated with pleural effusion. A perihilar alveolar opacification was seen on the left lung (Figure 1).

The chest computed tomography showed volumetric reduction of the right lung parenchyma, which had totally collapsed, with bronchial and alveolar areas filled in by fluid content (Figure 2). The basal segments had heterogeneous attenuation with some parenchymal calcifications, which suggested the presence of a poorly delimited expanding mass (Figure 3). Right pleural enhancement by contrast medium and effusion was present. Ground-glass opacity areas associated with diffuse interstitial thickening displaying a mosaic pattern was present in the left lung (Figure 4). Poorly defined subpleural nodules were also depicted. Dilation of the trunk of the pulmonary artery was observed. Calcified mediastinal lymph nodes were seen without evidence of mediastinal lymph node enlargement.

Thoracentesis resulted in serohemorrhagic exudate effusion drainage. Cytological examination failed to show malignancy.

The lower limbs venous echo Doppler revealed thrombosis of right popliteal vein and thrombosis of the left femoral veins, which led to the addition of enoxaparin to his prescription.

The bronchoscopy showed that the left bronchial tree, the right main bronchus, and the right upper lobe bronchus were free from lesions. The secondary carina was warped, and the intermediate bronchus showed converging grooves and granular mucosa. The distal bronchial ostia (to the inferior and medium lobes) showed reduced caliber that could not be surmounted. Bronchial biopsies were carried out on the tenth day of hospitalization.

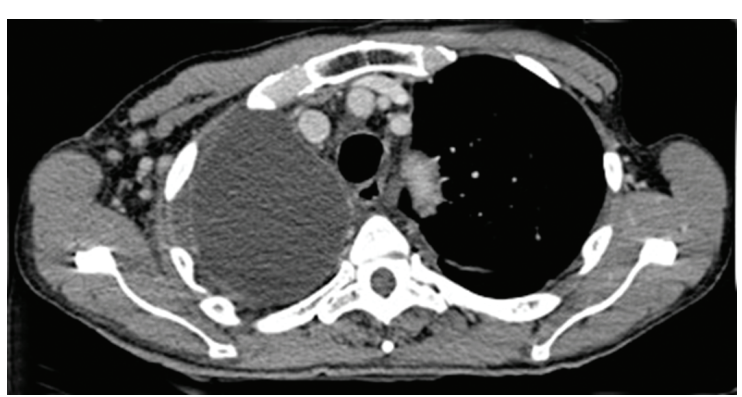

Figure 2 - Axial computed tomography (CT) of the chest - mediastinal window - showing voluminous hypodense collection with discrete pleural thickening and enhancement associated with retraction of the apex of the right hemithorax. 
Table 1 - Admission laboratory workup

\begin{tabular}{cccccc}
\hline & & RV & & RV \\
\hline Hemoglobin & 12.3 & $12.3-15.3 \mathrm{~g} \%$ & Creatinine & 0.5 & $0.4-1.3 \mathrm{mg} / \mathrm{dL}$ \\
Hematocrit & 37.6 & $36.0-45.0 \%$ & Potassium & 4.5 & $3.5-5.0 \mathrm{mEq} / \mathrm{L}$ \\
Leucocytes & 25.4 & $4.4-11.3 \times 10^{3} / \mathrm{mm}^{3}$ & Sodium & 135 & $136-146 \mathrm{mEq} / \mathrm{L}$ \\
Bands & 0 & $1-5 \%$ & ALT & 18 & $9-36 \mathrm{U} / \mathrm{L}$ \\
Segmented & 95 & $45-70 \%$ & AST & 18 & $10-31 \mathrm{U} / \mathrm{L}$ \\
Eosinophils & 0 & $1-4 \%$ & Total bilirubin & 0.39 & $0.3-1.2 \mathrm{mg} / \mathrm{dL}$ \\
Basophils & 0 & $0-2.5 \%$ & Glucose (random) & 109 & $70-140 \mathrm{mg} / \mathrm{dL}$ \\
Lymphocytes & 3 & $18-40 \%$ & Cai+ & 324 & 1.11 \\
Monocytes & 2 & $2-9 \%$ & Total protein & 7.0 & $1.11-1.4 \mathrm{mmol} / \mathrm{L}$ \\
Platelets & $453.10^{3}$ & $150-400 \times 10^{3} / \mathrm{mm}^{3}$ & Albumin & 3.6 & $7-8 \mathrm{~g} / \mathrm{dL}$ \\
CRP & 158 & $<5 \mathrm{mg} / \mathrm{L}$ & PT (INR) & 1.4 & $3-5 \mathrm{~g} / \mathrm{dL}$ \\
BUN & 13 & $5-25 \mathrm{mg} / \mathrm{dL}$ & 1 & \\
\hline
\end{tabular}

$\mathrm{ALT}=$ alanine aminotransferase; $\mathrm{AST}$ = aspartate aminotransferase; $\mathrm{BUN}=$ blood urea nitrogen; Cai+ = ionized calcium; $\mathrm{CRP}=\mathrm{C}$-reactive protein; $\mathrm{LDH}=$ lactic dehydrogenase, $\mathrm{PT}=$ prothrombin time; $\mathrm{RV}=$ reference value.

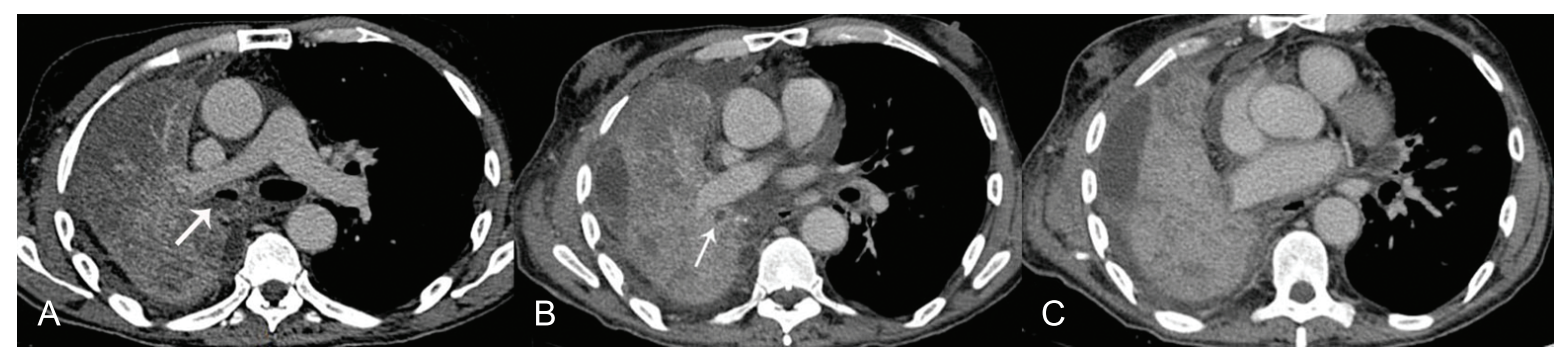

Figure 3 - Axial CT of the chest - mediastinal window. A - Hypodense liquid content in the right main bronchus (arrow) and heterogeneous enhancement of the lung parenchyma; $\mathbf{B}$ - Hypodense liquid content within the interlobar bronchus (arrow); C - Irregularity and thinning of the pulmonary veins close to the left atrium. Note pleural and pericardial effusion as well as bilateral gynecomastia.
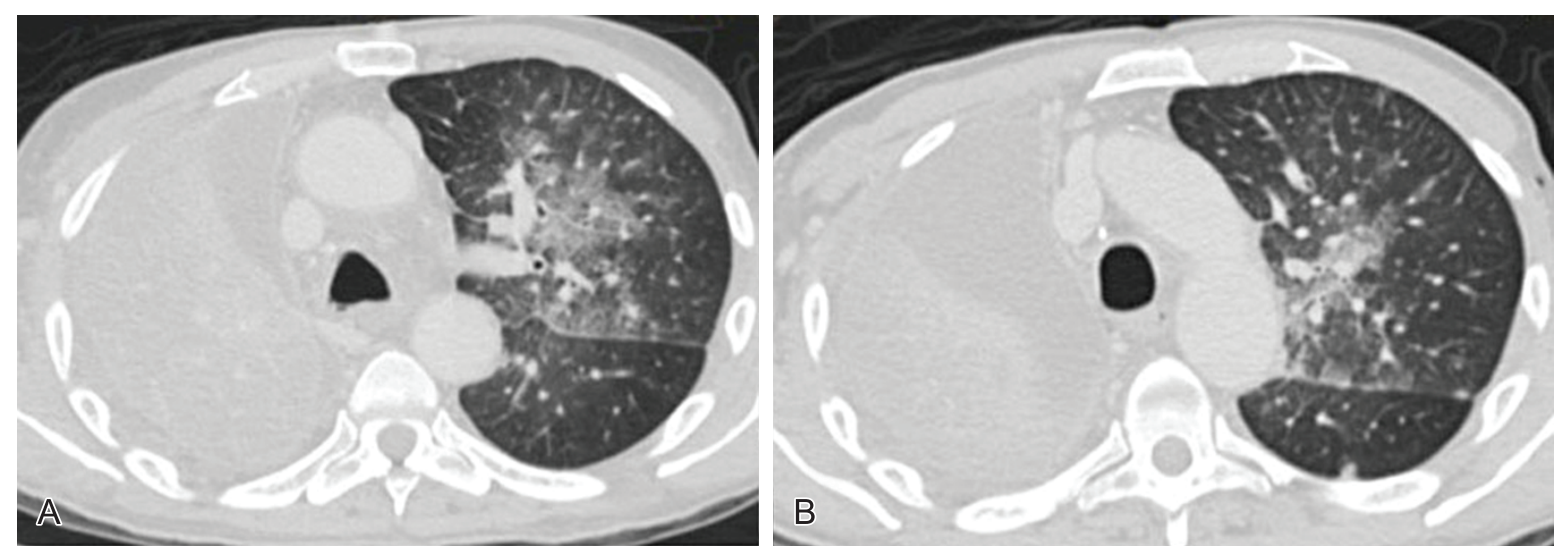

Figure 4-Axial CT of the chest - pulmonary window. A and B - Fissure thickening with micronodules. Septal thickening and ground glass opacities associated with septal thickening ("crazy paving") in the left upper lobe.

Clinical outcome was unfavorable accompanied by a worsening of the patient's respiratory function and then shock, despite supportive therapy. The patient died after 12 days of hospitalization without a precise diagnosis of pulmonary pathology.
On the day of death, the biopsies performed during bronchoscopy were completed and disclosed a diagnosis of non-small cell lung carcinoma infiltrating the bronchial mucosa, accompanied by squamous metaplasia with moderate dysplasia of the respiratory epithelium. Immunohistochemical 
analyses were performed on the autopsy samples. Serum alpha-fetoprotein (AFP), carcinoembryonic antigen (CEA), and beta-human chorionic gonadotrophin (beta-hCG) were tested in stored blood samples, after patient's death. Serum AFP and beta-hCG determinations were normal, but CEA was $580 \mu \mathrm{g} / \mathrm{L}$ (reference value $<5 \mu \mathrm{g} / \mathrm{L}$ ).

\section{Autopsy}

The external examination of the body showed an emaciated, cachectic man. Bilateral jugular stasis and gynecomastia were evident. A large volume serosanguineous pleural effusion with multiple adhesions between the lungs, pleura, diaphragm, and the rib cage were observed upon opening the thoracic cavity. These findings were more prominent in the right hemithorax. Invasion of the pericardium led to a fibrinous and hemorrhagic pericarditis.

Examination of the right lung revealed extensive replacement of the inferior lobe by a grayish diffuse neoplasia, which mimicked a lobar pneumonia ("pneumonia-like" gross pattern). A dense fibrous pleural thickening encased the right pulmonary lobes and the inferior airways were obstructed by tumor invasion. This pneumonia-like pattern also affected the superior lobe of the left lung. Microscopic dissemination through lymphatics, pleura, and airways was detected (Figure 5).

Histological examination revealed mucinproducing neoplastic cells arranged in solid sheets or dyscohesive clusters, which filled the alveolar spaces (Figure 5). Signet-ring-like cells and mucinpositive cytoplasmic vacuoles were present. Moderately differentiated areas with columnar cells and acini as well as foci of keratinization and necrosis were seen scattered through the tumor (Figure 6).

Other areas (about 20\%) showed abundant eosinophilic or clear cytoplasm with distinct cell borders, cytoplasmic grumous ("Mallory bodylike") and globoid PAS-positive hyalines. Nuclear pseudoinclusions were occasionally seen (Figure 7).
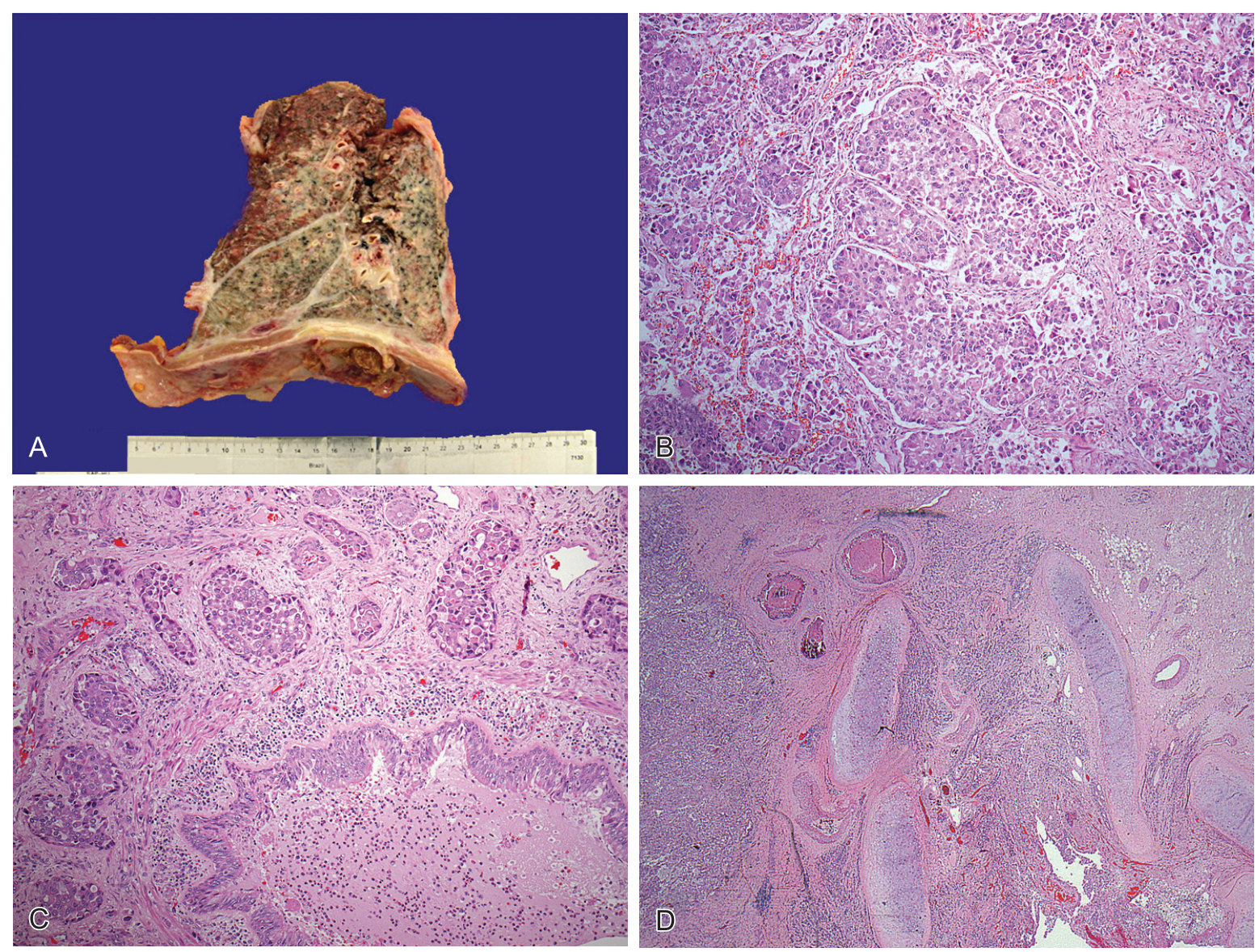

Figure 5 - A - Gross examination of right lung showing pleural thickening, adherence to diaphragm, and pneumonia-like pattern; B - Photomicrography of tumor cells filling alveolar spaces (air dissemination) (H\&E 200x); C - Photomicrography of tumor lymphatic dissemination; note fluid edema in bronchiolar lumen (right bottom) (H\&E 200x); D - Photomicrography of segmental bronchus invaded and obliterated by tumor (H\&E original magnification $12.5 \times$ ). 

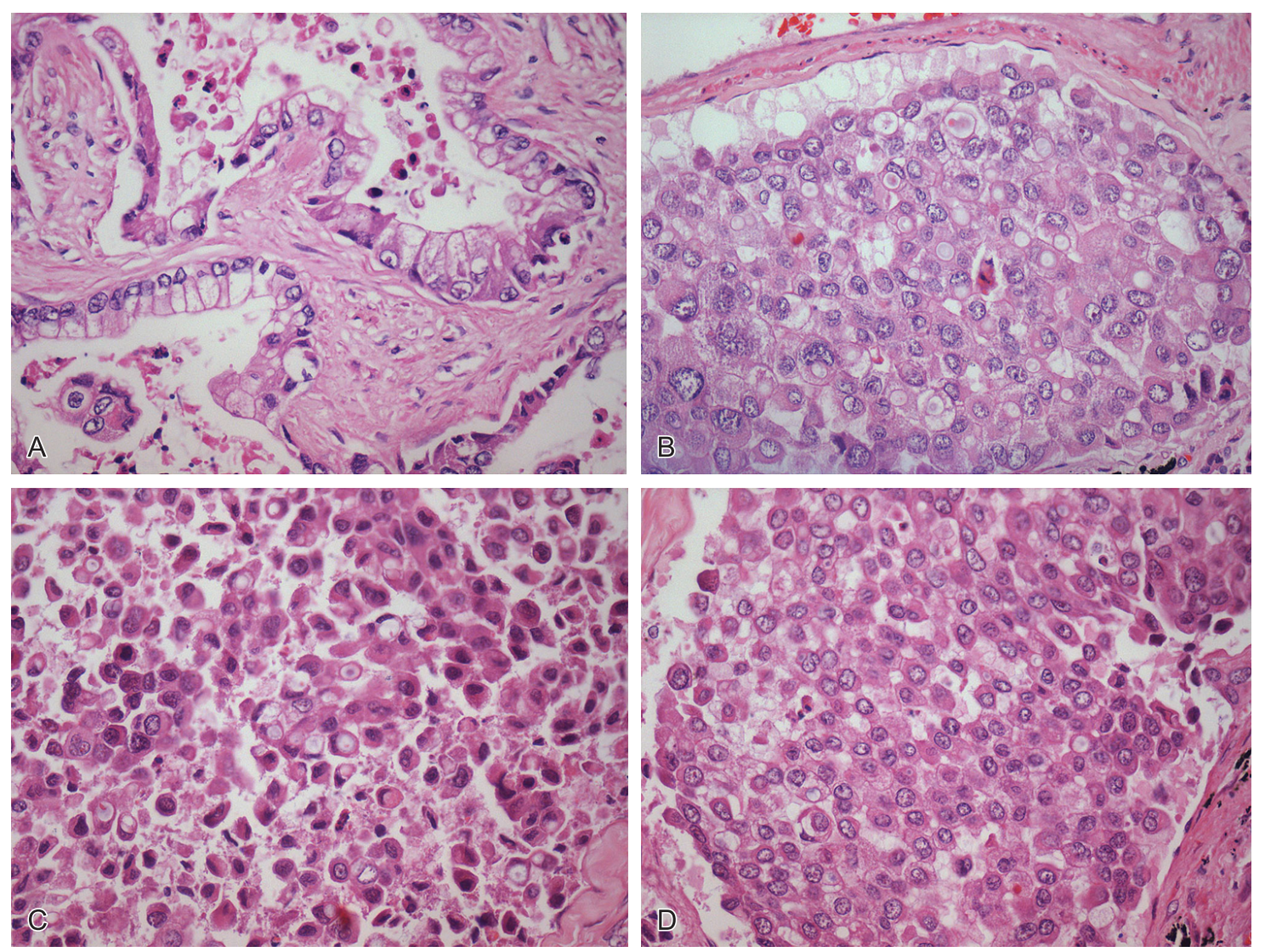

Figure 6 - Photomicrographs. A - Acinar pattern with columnar cells (H\&E 400x); B - Solid pattern with mucin vacuoles (H\&E 400x); C - Signet-ring cells (H\&E 400x); D - Sheet-like pattern of poorly cohesive cells with eosinophilic cytoplasm (H\&E 400x).
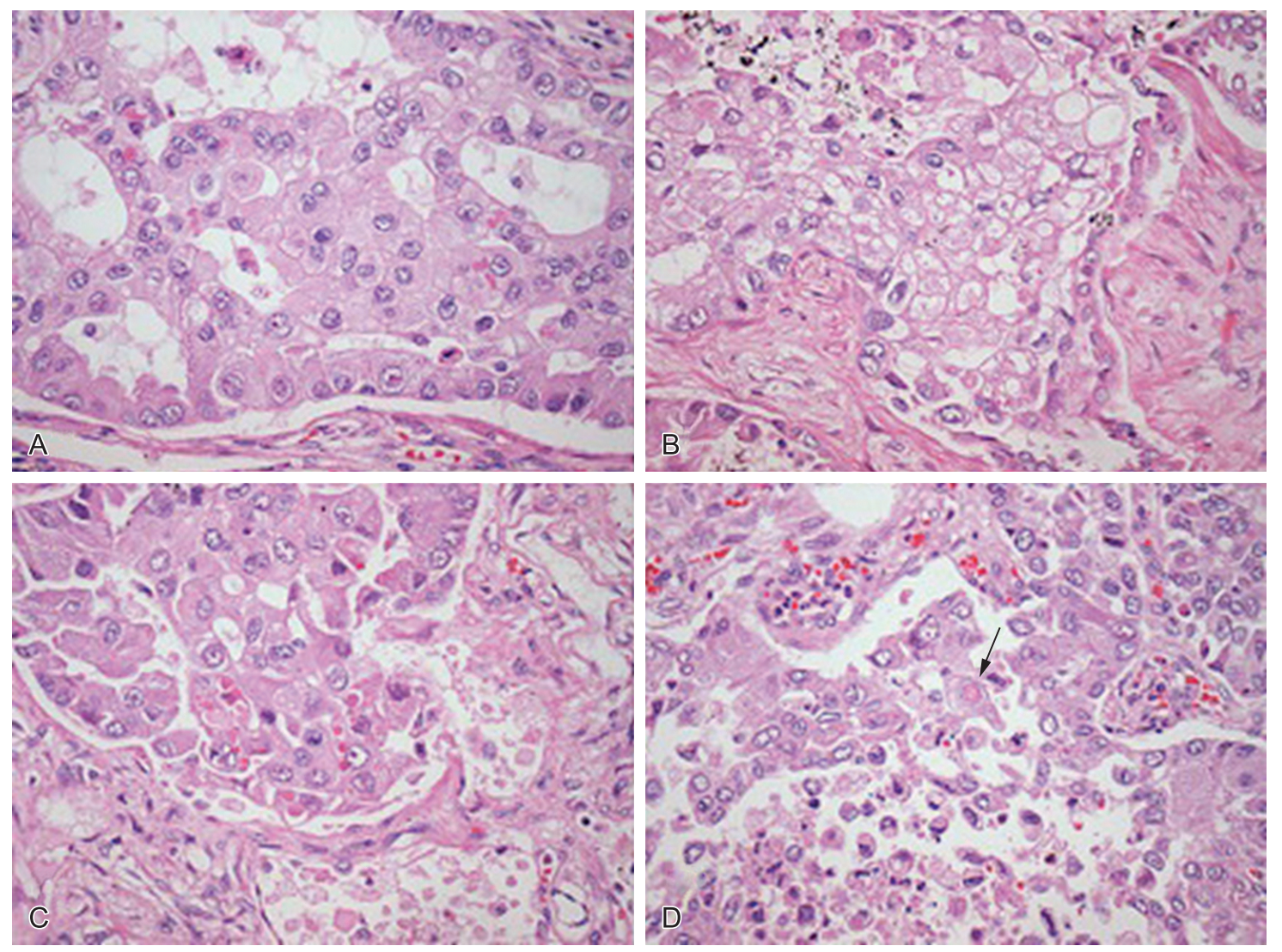

Figure 7 - Photomicrographs. A - Large eosinophilic cells in focal trabecular pattern (H\&E 400x); B - Clear cells (H\&E 400x); C - Eosinophilic globules (H\&E 400x); D - Large nuclear pseudoinclusion (arrow) (H\&E $400 \times)$. 
These features suggested a poorly differentiated adenocarcinoma with hepatoid features.

Immunohistochemical stains were positive for keratin 7, polyclonal CEA in a diffuse pattern, AFP (multifocal) and hepatocyte paraffin 1 (HepPar-1) antibody. HepPar-1 staining was diffuse. Thyroid transcription factor-1 (TTF-1) showed a diffuse granular cytoplasmic staining of the neoplastic cells, and only focal nuclear positivity. Staining for keratins $5 / 6$ was focally positive, especially in the foci of keratinization (Figures 8 and 9). The reactions were negative for keratin 20, chromogranin, synaptophysin, p63 protein, and beta-hCG.

Multiple bilateral emboli that originated from deep venous thrombosis in the left popliteal and common iliac veins were present in large and medium caliber branches of the pulmonary artery. Additionally, histological examination revealed local arterial thrombosis entrapped in tumor areas and fibromuscular narrowing and thickening of small pulmonary arteries. These findings were suggestive of pulmonary hypertension attributed to local thrombosis and to possible recurrent thromboembolism. Microscopic examination did not demonstrate thrombus in different stages of organization, however, previous thromboembolic events in a patient with advanced cancer could not be ruled out. Right cardiac chambers and main pulmonary arteries were preserved.

Lung edema, alveolar hemorrhage and diffuse alveolar damage were present. The left ventricle wall had severe concentric hypertrophy, left atrium was mildly dilated and hyaline arteriolosclerosis was detected in the spleen. These findings were consistent with previous systemic arterial hypertension which might have contributed to the final events. Metastatic disease was found in the right adrenal gland and mediastinal, para-aortic and peripancreatic lymph nodes.

\section{DISCUSSION}

In 1990, Ishikura et al. ${ }^{1}$ described hepatoid lung adenocarcinomas as tumors with a mixture
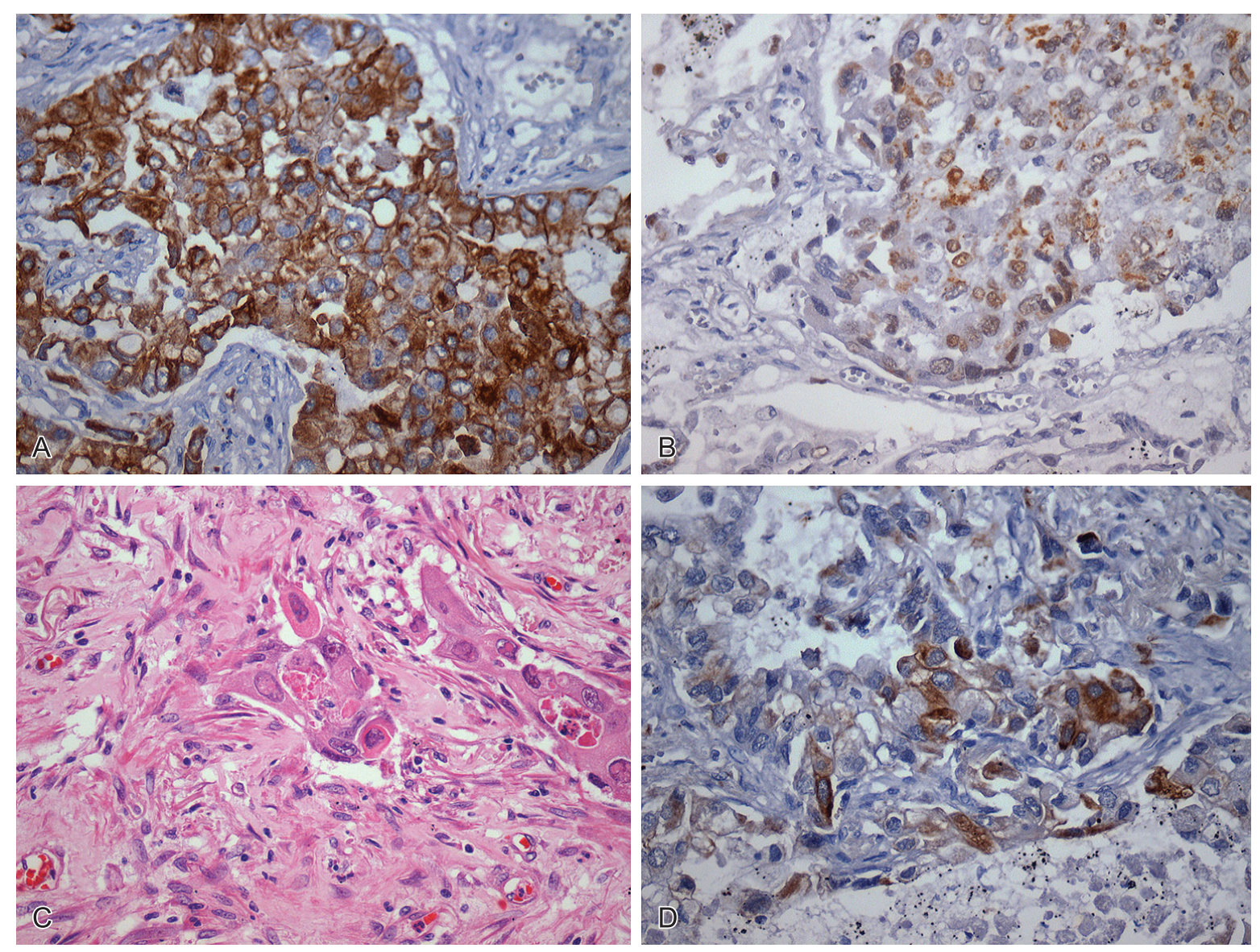

Figure 8 - Photomicrographs. A - Immunohistochemistry for keratin 7 (H\&E 400x); B - Focal nuclear TTF-1 immunostaining (H\&E 400x); C - Focal keratinization (H\&E 400x); D - Focal immunostaining for keratin 5/6 (H\&E 400x). 

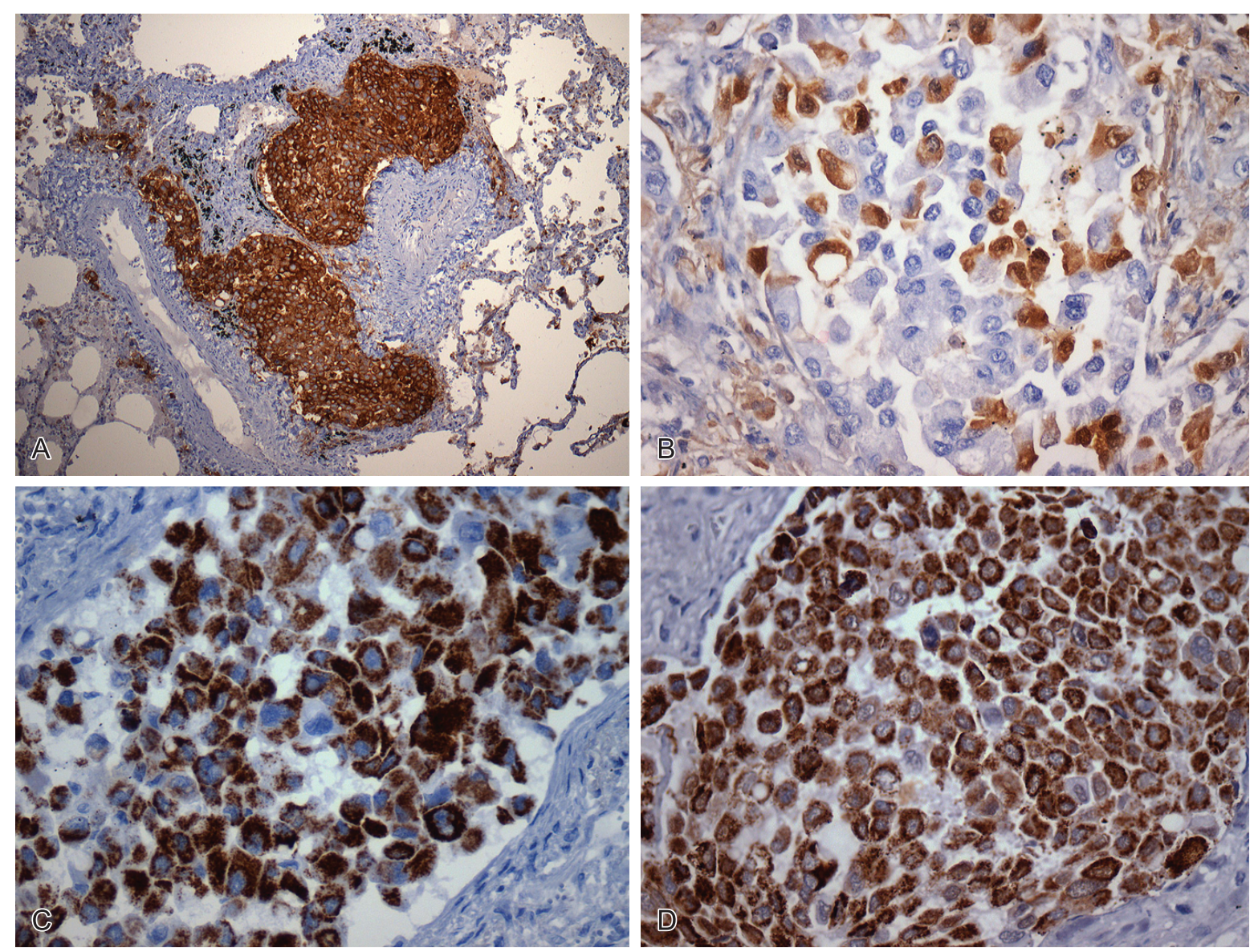

Figure 9 - Photomicrographs. A - Immunohistochemistry for CEA with diffuse staining (H\&E 100x); B - Multifocal immunostaining for AFP (H\&E 400x); C - Diffuse Hep-par (H\&E 400x); D - Cytoplasmatic granular TTF-1 staining (H\&E 400x).

of tubular or papillary adenocarcinoma with sheetlike or trabecular proliferation of neoplastic cells with abundant eosinophilic cytoplasm and centrally located nuclei, resembling hepatocellular carcinoma cells. Accordingly, hepatoid lung adenocarcinoma is a major histological subtype in clinically AFP. producing lung adenocarcinomas. Other histological features include cuboidal or polygonal cells with clear cytoplasm, PAS-positive diastase-resistant hyaline globules and vascular lake-like cystic spaces lined by tumor cells. ${ }^{2}$ Lazaro et al. $^{3}$ considered abundant eosinophilic cytoplasm and evidence of AFP production as the minimum histological criteria for a diagnosis of hepatoid carcinoma.

In a recent review of 261 published cases of hepatoid adenocarcinomas, Metzgeroth et al. ${ }^{4}$ found that the most common primary site was the stomach $(63 \%)$, followed by ovaries $(10 \%)$, lung $(5 \%)$, gallbladder, pancreas, and uterus (4\% each). Immunohistochemical positivity for AFP (88\%) and HepPar-1 (63\%) were important diagnostic features. Other extrahepatic organs include ampulla of Vater, kidney, and urinary bladder. ${ }^{3,5}$ Fornasa $^{6}$ reported one case of metastatic hepatoid lung carcinoma to soft tissues of the shoulder.

We report on a patient with a poorly differentiated, advanced lung adenocarcinoma that showed some morphological and immunohistochemical hepatoid features. Although sinusoid-like spaces or trabecular architecture with the typical round and centrally located nuclei of hepatocytes were not observed, some areas demonstrated sheets of cells with eosinophilic or clear cytoplasm, distinct cell borders, and hyaline PAS-positive cytoplasmic globules that were reminiscent of hepatocellular differentiation and set prompt immunohistochemical investigation.

Immunohistochemistry revealed positivity for AFP, HepPar-1 and cytoplasmic granular staining of TTF-1. HepPar-1 is quite specific for hepatocellular differentiation, but other adenocarcinomas may be positive as well, mainly gastric poorly differentiated and signet-ring cell adenocarcinomas (about $50 \%) .{ }^{7}$ Lung adenocarcinomas are infrequently stained $(4-8 \%){ }^{8}$ Maitra et al. $^{9}$ demonstrated HepPar-1 expression in six of seven hepatoid 
adenocarcinomas of the gastrointestinal tract. In the report and review by Papatsimpas et al., ${ }^{5}$ HepPar-1 was positive in two of four tested lung hepatoid adenocarcinomas.

Although not specific, cytoplasmic granular staining for TTF-1 has been reported as a marker of hepatocellular differentiation. This pattern is rarely seen in other adenocarcinomas. ${ }^{10,11}$ Anti-TTF-1 antibodies seem to react with a different epitope of the hepatocellular mitochondrial urea cycle enzyme carbamoyl phosphate synthetase 1 , which is the antigen for the HepPar-1 antibody, ${ }^{12,13}$ and not with a hypothetical alternative splicing product of the TTF-1 gene in hepatocytes. ${ }^{14}$

The serum AFP was normal in the present case; however, neither serum- nor tissue-expressed AFP are required for diagnosis since this is mostly based on histopathological criteria. Nagai et al. ${ }^{2}$ demonstrated that gastric carcinomas with hepatoid features have a worse prognosis than conventional carcinomas regardless of AFP detection by immunohistochemistry. Serum AFP levels have been shown to decrease after tumor resection and increase with recurrent disease, so it may be a useful tool for diagnosis and follow-up purposes. , $3,15,16^{-16}$

Lung hepatoid adenocarcinoma is diagnosed at an average age of 60 years (range 36-82), predominantly in males. ${ }^{5}$ There is not a consensus on the specific amount of hepatoid features for pathological diagnosis. The prognosis for hepatoid lung carcinoma and AFP-producing pulmonary carcinoma has not been fully elucidated because of the low number of reported cases. However, it seems to be associated with high proliferative indexes and early metastatic potential. ${ }^{1,16,17}$ For instance, hepatoid carcinomas of the stomach have been associated with a high incidence of vascular invasion and metastases. ${ }^{2}$ Although this feature has not been established for lung hepatoid adenocarcinomas, the present case showed many sites of vascular invasion with obliteration of pulmonary veins and adrenal metastasis. On the other hand, cases with early stage disease have been curatively resected..$^{18,19}$

Three mechanisms of carcinogenesis are suggested for hepatoid adenocarcinomas. First, AFP-producing lung carcinoma may originate from respiratory epithelium capable of multipotential differentiation. ${ }^{16}$ Second, an adenocarcinoma acquires the hepatic phenotype in the process of tumor progression. ${ }^{20}$ Third, (the most unlikely) the hepatoid lung carcinoma originates in ectopic liver tissue. ${ }^{1}$

Hepatoid and signet-ring cell cytomorphology as well as solid, papillary and micropapillary architectural patterns have been associated with chromosomal rearrangements leading to the constitutive activation of anaplastic lymphoma receptor tyrosine kinase (ALK). ALK rearrangements define a category of lung adenocarcinomas that may be suitable for targeted therapy with the ALK inhibitor crizotinib. ${ }^{21,22}$ The presence of hepatoid, signet-ring and solid features in the present case raise the hypothesis of an ALK-positive lung adenocarcinoma.

The pneumonia-like gross pattern is classically associated with bronchioloalveolar mucinous carcinoma, although most pneumoniatype bronchioloalveolar carcinomas show a mixture with other subtypes, including an invasive component. ${ }^{23,24}$ To the best of our knowledge, a pneumonia-like gross pattern has not yet been reported in hepatoid lung adenocarcinoma. In the present case, a pneumonia-like consolidation could be attributable to the filling of alveolar spaces by tumor cells, inflammation, and desmoplastic reaction.

\section{CONCLUSION}

The immediate cause of death in the present case was pulmonary thromboembolism, a wellknown paraneoplastic manifestation of lung cancer. Acute pulmonary edema as related to left ventricular hypertrophy and diffuse alveolar damage may have contributed as well. Gynecomastia has been reported in cases of lung cancer, but beta-hCG is usually detected in the serum or in the tumor in these cases. ${ }^{25,26}$ In the present case, serum betahCG levels were normal and immunohistochemistry was negative. Gynecomastia might be related to other hormonal imbalances or ectopic prolactin production, but further hormonal workup was not available in this case.

\section{REFERENCES}

1. Ishikura H, Kanda M, Ito M, Nosaka K, Mizuno K. Hepatoid adenocarcinoma: a distinctive histological subtype of alphafetoprotein-producing lung carcinoma. Virchows Arch A Pathol 
Anat Histopathol. 1990;417(1):73-80. PMid:1694332. http:// dx.doi.org/10.1007/BF01600112

2. Nagai E, Ueyama T, Yao T, Tsuneyoshi M. Hepatoid adenocarcinoma of the stomach. A clinicopathologic and immunohistochemical analysis. Cancer. 1993;72(6):1827-35. http://dx.doi. org/10.1002/1097-0142(19930915)72:6<1827::AIDCNCR2820720606>3.0.CO;2-8

3. Lazaro J, Rubio D, Repolles M, Capote L. Hepatoid carcinoma of the ovary and management. Acta Obstet Gynecol Scand. 2007;86(4):498-9. PMid:17486476. http:// dx.doi.org/10.1080/00016340600593117

4. Metzgeroth G, Ströbel P, Baumbusch T, Reiter A, Hastka J. Hepatoid adenocarcinoma - review of the literature illustrated by a rare case originating in the peritoneal cavity. Onkologie. 2010;33(5):263-9. PMid:20502062. http://dx.doi. org/10.1159/000305717

5. Papatsimpas G, Kamposioras K, Goula K, et al. Hepatoid pancoast tumor. A case report and review of the literature. Lung Cancer. 2012;77(2):239-45. PMid:22677427. http:// dx.doi.org/10.1016/j.lungcan.2012.05.102

6. Fornasa F. Soft-Tissue Localization of hepatoid adenocarcinoma: first case report. Case Rep Oncol. 2010;3(2):212-7. PMid:20740199 PMCid:2920002. http://dx.doi.org/10.1159/000317419

7. Fan Z, Van de Rijn M, Montgomery K, Rouse RV. Hep par 1 antibody stain for the differential diagnosis of hepatocellular carcinoma: 676 tumors tested using tissue microarrays and conventional tissue sections. Mod Pathol. 2003;16(2):137-44. PMid:12591966. http://dx.doi. org/10.1097/01.MP.0000052103.13730.20

8. Lugli A, Tornillo L, Mirlacher M, Bundi M, Sauter G, Terracciano LM. Hepatocyte paraffin 1 expression in human normal and neoplastic tissues: tissue microarray analysis on 3,940 tissue samples. Am J Clin Pathol. 2004;122(5):721-7. PMid:15491968. http://dx.doi. org/10.1309/KC09YTF2M4DLUYQ6

9. Maitra A, Murakata LA, Albores-Saavedra J. Immunoreactivity for hepatocyte paraffin 1 antibody in hepatoid adenocarcinomas of the gastrointestinal tract. Am J Clin Pathol. 2001;115(5):689-94. PMid:11345832. http://dx.doi. org/10.1309/5C2C-FP3H-GE7Q-2XJ5

10. Pan CC, Chen PC, Tsay SH, Chiang H. Cytoplasmic immunoreactivity for thyroid transcription factor-1 in hepatocellular carcinoma: a comparative immunohistochemical analysis of four commercial antibodies using a tissue array technique. Am J Clin Pathol. 2004;121(3):343-9. PMid:15023038. http://dx.doi. org/10.1309/8BM44NK626997DJJ

11. Wieczorek TJ, Pinkus JL, Glickman JN, Pinkus GS. Comparison of thyroid transcription factor-1 and hepatocyte antigen immunohistochemical analysis in the differential diagnosis of hepatocellular carcinoma, metastatic adenocarcinoma, renal cell carcinoma, and adrenal cortical carcinoma. Am J Clin Pathol. 2002;118(6):911-21. PMid:12472285. http://dx.doi.org/10.1309/KKDP-MND2W794-P9EH

12. Pang $\mathrm{Y}$, Von Turkovich $\mathrm{M}, \mathrm{Wu} \mathrm{H}$, et al. The binding of thyroid transcription factor-1 and hepatocyte paraffin 1 to mitochondrial proteins in hepatocytes: a molecular and immunoelectron microscopic study. Am J Clin Pathol. 2006;125(5):722-6. PMid:16707373. http://dx.doi. org/10.1309/EBCB6H54K1N2P9QL

13. Butler SL, Dong H, Cardona D, et al. The antigen for Hep Par 1 antibody is the urea cycle enzyme carbamoyl phosphate synthetase 1. Lab Invest. 2008;88(1):78-88. PMid:18026163. http://dx.doi.org/10.1038/labinvest.3700699

14. Gu K, Shah V, Ma C, Zhang L, Yang M. Cytoplasmic immunoreactivity of thyroid transcription factor-1 (clone 8 G7G3/1) in hepatocytes: true positivity or cross-reaction? Am J Clin Pathol. 2007;128(3):3828. PMid:17709311. http://dx.doi.org/10.1309/ CADCVWHR2QF6JMVN

15. Arnould L, Drouot F, Fargeot P, et al. Hepatoid adenocarcinoma of the lung: report of a case of an unusual alpha-fetoprotein-producing lung tumor. Am J Surg Pathol. 1997;21(9):1113-8. PMid:9298890. http://dx.doi. org/10.1097/00000478-199709000-00018

16. Hiroshima K, lyoda A, Toyozaki T, et al. Alpha-fetoproteinproducing lung carcinoma: report of three cases. Pathol Int. 2002;52(1):46-53. PMid:11940206. http://dx.doi. org/10.1046/j.1440-1827.2002.01311.x

17. Nasu M, Soma T, Fukushima H, Kudo K, Matsubara O. Hepatoid carcinoma of the lung with production of alphafetoprotein and abnormal prothrombin: an autopsy case report. Mod Pathol. 1997;10(10):1054-8. PMid:9346187.

18. Carlinfante G, Foschini MP, Pasquinelli G, Scotti R, Cavazza A. Hepatoid carcinoma of the lung: a case report with immunohistochemical, ultrastructural and in-situ hybridization findings. Histopathology. 2000;37(1):88-9. PMid:10931226. http://dx.doi.org/10.1046/j.1365-2559.2000.00955-5.x

19. Hayashi $\mathrm{Y}$, Takanashi $\mathrm{Y}$, Ohsawa $\mathrm{H}$, Ishii $\mathrm{H}$, Nakatani Y. Hepatoid adenocarcinoma in the lung. Lung Cancer. 2002;38(2):211-4. http://dx.doi.org/10.1016/S01695002(02)00214-3

20. Kishimoto T, Nagai $Y$, Kato K, Ozaki D, Ishikura H. Hepatoid adenocarcinoma: a new clinicopathological entity and the hypotheses on carcinogenesis. Med Electron Microsc. 2000;33(2):57-63. PMid:11810459. http://dx.doi. org/10.1007/s007950070002

21. Nishino M, Klepeis VE, Yeap BY, et al. Histologic and cytomorphologic features of ALK-rearranged lung adenocarcinomas. Mod Pathol. 2012;25(11):1462-72. PMid:22743652. http://dx.doi.org/10.1038/modpathol.2012.109 
22. Khozin S, Roth MJ, Rajan A, et al. Hepatoid carcinoma of the lung with anaplastic lymphoma kinase gene rearrangement. J Thorac Oncol. 2012;7(11):e29-31. PMid:23070248. http:// dx.doi.org/10.1097/JTO.0b013e3182697a23

23. Wislez M, Massiani MA, Milleron B, et al. Clinical characteristics of pneumonic-type adenocarcinoma of the lung. Chest. 2003;123(6):1868-77. PMid:12796162. http:// dx.doi.org/10.1378/chest.123.6.1868

24. Garfield DH, Cadranel JL, Wislez M, Franklin WA, Hirsch FR. The bronchioloalveolar carcinoma and peripheral adenocarcinoma spectrum of diseases. J Thorac
Oncol. 2006;1(4):344-59. PMid:17409882. http://dx.doi. org/10.1097/01243894-200605000-00014

25. Liu G, Rosenfield Darling ML, Chan J, Jaklitsch MT, Skarin AT. Gynecomastia in a patient with lung cancer. J Clin Oncol. 1999;17(6):1956. PMid:10561237.

26. Okutur K, Hasbal B, Aydin K, et al. Pleomorphic carcinoma of the lung with high serum beta-human chorionic gonadotropin level and gynecomastia. J Korean Med Sci. 2010;25(12):18058. PMid:21165299 PMCid:2995238. http://dx.doi.org/10.3346/ jkms.2010.25.12.1805

\section{Conflict of interest: None}

Submitted on: $16^{\text {th }}$ December 2012

Accept on: $14^{\text {th }}$ March 2013

Correspondence: Departamento de Patologia do Hospital das Clínicas

Faculdade de Medicina da Universidade de São Paulo

Av. Dr. Enéas Carvalho de Aguiar, $155-10^{\circ}$ andar - Cerqueira Cesar - São Paulo/SP - Brazil

Phone: +55 (11) 951564366

E-mail: livia_barreira@yahoo.com.br 